\title{
COMPARATIVE ANALYSIS OF BRACING SYSTEMS IN A STEEL STRUCTURE SHED
}

\author{
${ }^{1}$ Anunciação Jr, N.C, ${ }^{2}$ Souza, L.G.Q, ${ }^{3}$ Pereira, A.A, ${ }^{4}$ Ribeiro, C.B, and ${ }^{5}$ Barboza, M. D. S.
}

\author{
Centro Universitário ICESP \\ QS 05 Rua 300 Lote 01 - Águas Claras, Brasília - DF, Brasil. \\ Centro Universitário Euro Americano - UNIEURO \\ Av. das Castanheiras, s/n - Lote 3700 - Águas Claras, Brasília - DF, Brasil. \\ 1engnjunior@gmail.com; ${ }^{2}$ luanagomes644@gmail.com; ${ }^{3}$ aandressaabrantes@gmail.com; \\ eng.cleysonbribeiro@gmail.com; ${ }^{5}$ mdsbarboza.10@gmail.com;
}

Key Words: Steel Structure, Bracing Systems, Horizontal Actions, Displacement, Efficiency.

\begin{abstract}
The sheds, usually in metal structure, are commonly used for commercial or industrial establishments. Such structures can be designed under the laws established by the Ultimate Limit State (ULS) parameters, Service Limit Status (SLS) or Usage (SLU), even though many of them may be subject to large displacements caused by vibrations, static loads or, even the combination between both. The own weight's structure and the wind dynamic load combined is a perfect example how these structures are subjected to combined forces. Thus, alternatives to control or minimize the excessive displacement are needed. There are several methods of controlling vibration, and this paper presents the bracing system. Shed and 3 different bracing systems were designed, single diagonal, double diagonal and inverted $V$. These systems are designed to resist vertical and horizontal actions, and its main function is to provide stability to structures when they suffer from wind load action. In this paper NBR 6123/1988 was used to compute wind load. Numerical calculations were carried out in SAP2000 and Visual Ventos, in order to study the dynamic behaviour of the shed submitted to such actions. The analyses were restricted only to displacements in the $X$ and $Y$ directions. Afterwards, the reinforced structure was compared with that one without bracing. After the computations the minimal $X$ and $Y$ displacement were found for inverted $V$-shaped bracing system. Furthermore, the reinforce structure also provided great rigidity to the frame and a better distribution of the efforts in the structure nodes.
\end{abstract}

\section{INTRODUCTION}

Metallic structures are being used a way more in the civil construction, and it happens because of the fact that they are lighter, they get higher spans and they get high productivity in comparison to the ones in reinforced concrete. Taking advantages into consideration, this kind of structure is frequently used in sheds, which are related to different usages; no matter if to the industry, logistics, warehouses, among others.

Considering the Engineering, all the elements in the civil construction are under effect of static or dynamic actions. According to Chávez [4], structures that are usually subjected to dynamic loads require specific level of performance, stability and structural safety, which leads such relation to studies on techniques for the determination of answers to solicitant efforts, even when the dynamic excitation has its specific aspects, which differs it from its static equivalent for it has varieties that get changed along the time. Such time variability can also provide displacement, deformation and internal efforts.

Structures must be projected to hold such dynamic loads. However, with the alternative of building higher edifications with big spans, the need of increasing the rigidity of structures emerges once we consider the reduction of their capacity of adapting to dynamic actions. That 
said, when structures are subjected to dynamic loads, they become more susceptible to suffer with movements that cause deformation and displacement; such movements are called vibrations Carneiro [2].

In order to decrease the level of vibrations and at the same time to keep the slenderness of the structures, it has been developed, along the years, techniques for the structural control and the protection of structures that promote some changes in rigid property of the structural element, and, this way, to guarantee damping to the structure for the addition of external systems or for the action of external loads Carneiro [2].

The structural system of big buildings is usually composed by the junction of structural elements such as pillars, beams, slabs, and bracing systems. Such structural system must be dimensioned to resist to gravitational and lateral forces, and also other actions of usage. The choice of the structural system must also be related directly to the selection of the arrangement of structural elements designed to resist the horizontal and vertical efforts, guaranteeing an economical and safe way to the users Chaves [3].

Braces are elements composed by bars which are added to the structures aiming at preventing or reducing horizontal displacements, and/or vibrations, having as its main function to provide stability to structures that suffer wind action or others. Buildings which are considered large size, with several floors, the braces have to be taken as primordial in the project due to the wind load that can be very expressive through the operating life of the structure. In consequence, they will present more horizontal displacements. Buildings which are considered small size must be analyzed too; in case of being subjected to wind loads or having a great slenderness according to Matos [6]. In metallic sheds, due to openings and the positioning of the elements gantries and trusces) the braces must be used to oet better distribution of efforts, That said, the current was subjected to the shed which is taken Later, we designed oth
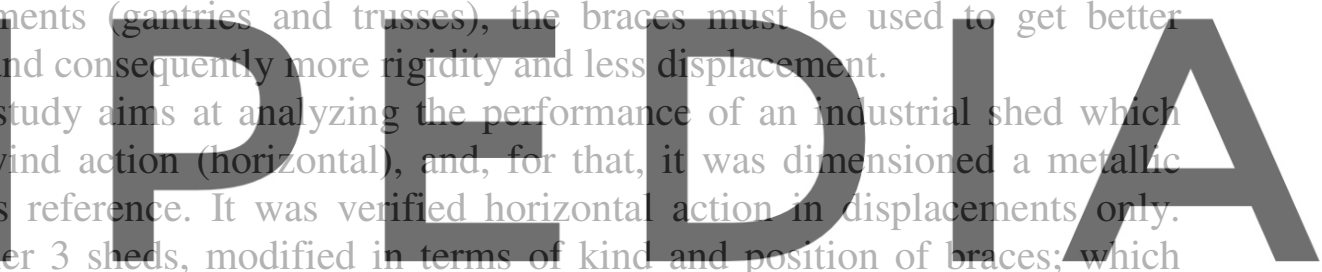

were simple diagonal, double diagonal and inverted V. In purpose to save time on the


structural models in a quickly way with no delay due to the verifications.

\section{MATERIALS E METHODS}

The shed that was taken for this study has the following basis dimension of project: 2 meters of length; 9 meters of height; six gantries separated at each 5,20 meters; pillars embedded in the foundation; it is also composed by two horizontal beams (one of them at 3,20 meters, and the other one at 5,80 meters from the ground), and it contains a central span of 6 meters. The figure 1, 2 and 3 show the shed project with the most important dimensions, indicating two entrance gates (one at the front face and another at the bottom), the windows along all the laterals, at both sides. Therefore, it was considered equally permeable for the calculation of the wind loads. 
Anunciação Jr, N.C, Souza, L.G.Q, Pereira, A.A, Ribeiro, C.B, and Barboza, M. D. S.

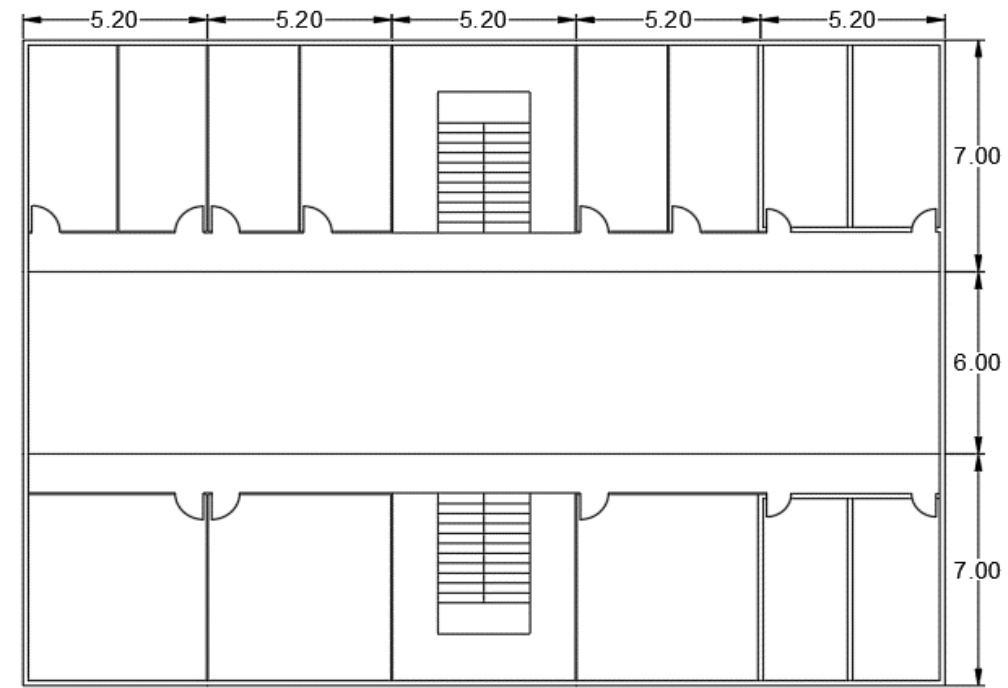

Figure 1 - Floor plan of the shed

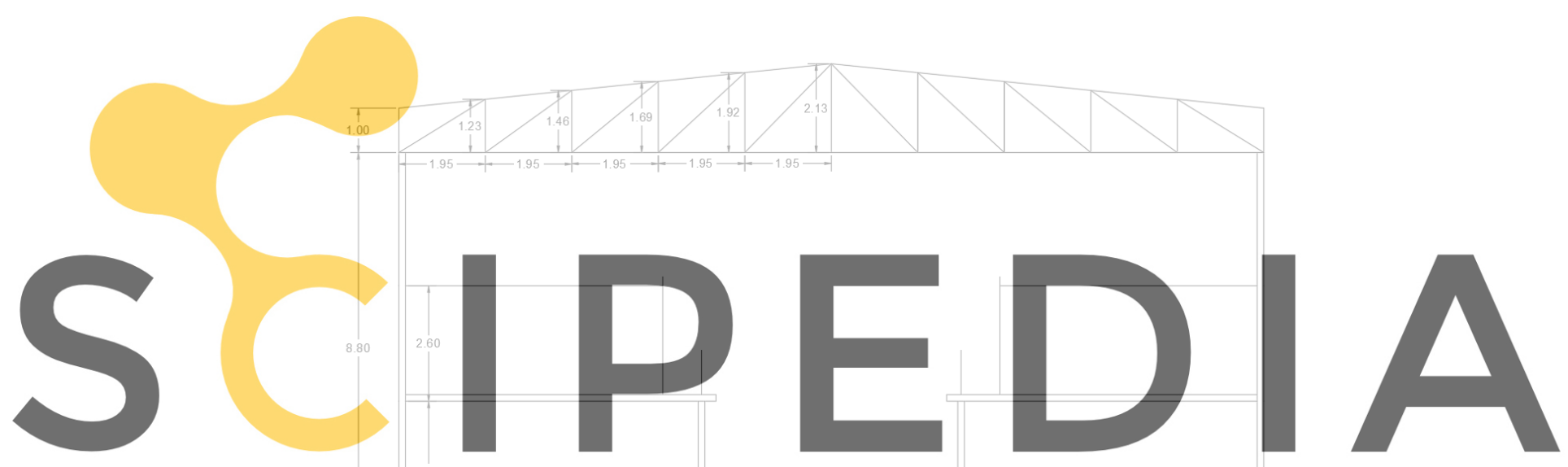

Register for free at https///www.scipedia.com to download the version without the watermark Figure 2 - Transversal intern section of the shed

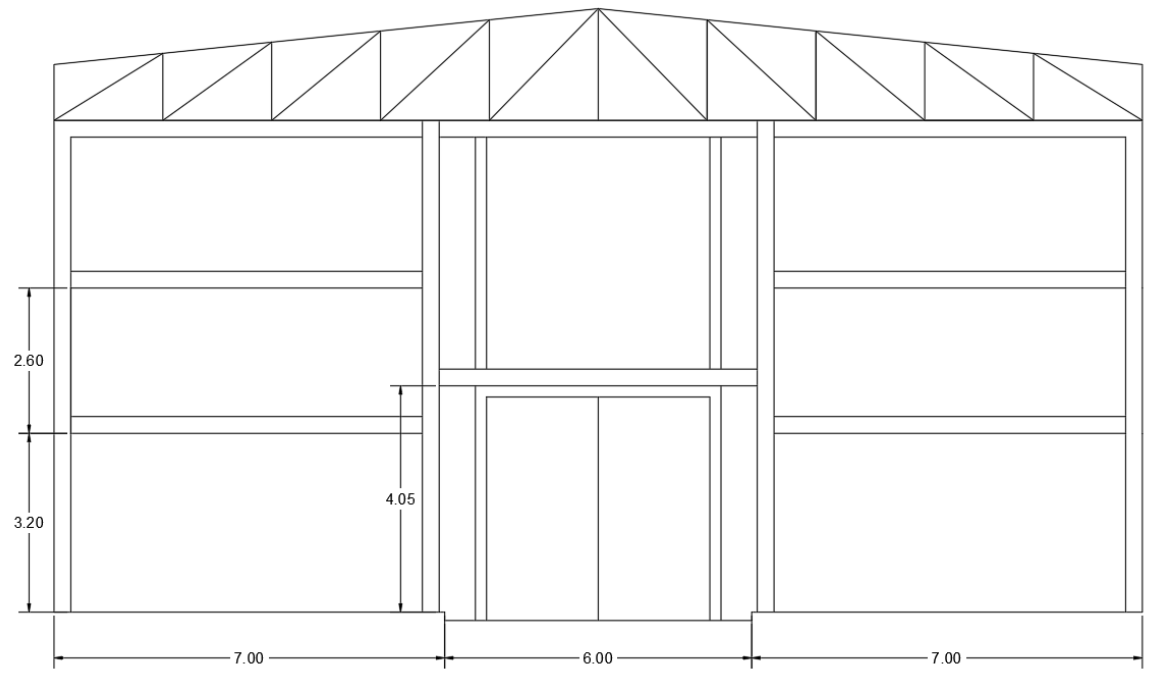

Figure 3 - Front section of the shed 


\subsection{Modeling}

Four structures were molded on the software SAP2000 with different kinds of bracings. They are listed below:

\subsubsection{Shed with no brace}

This structure was used to verify the displacements when there is no use of braces. The figure 4 shows the 3D sight, the front and the lateral of the structure, and from it, bars were added in different directions, configuring the kind of brace.

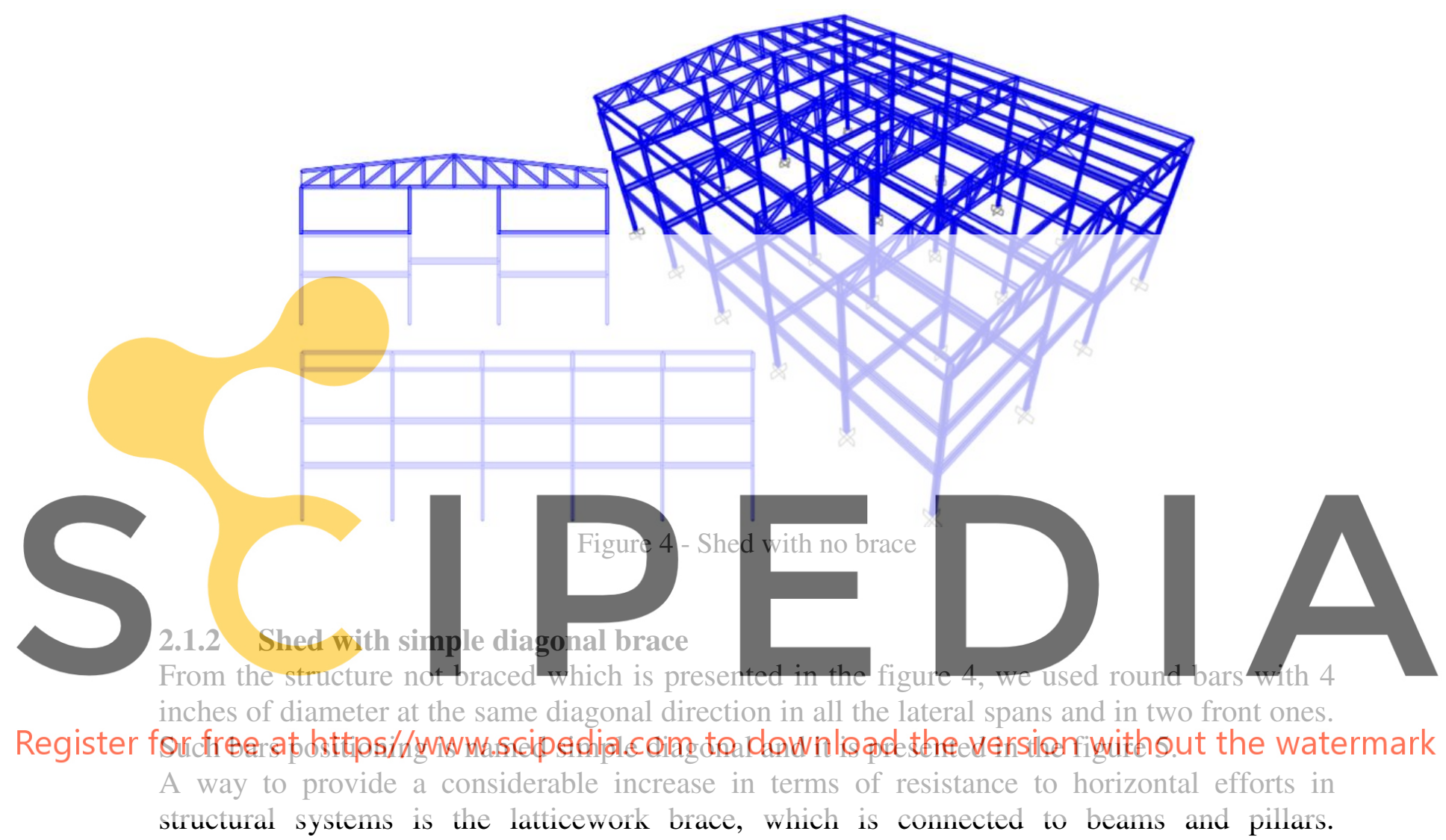

According to Smith and Coull [8], this kind of system produces, efficiently, an increase on the lateral resistance due to its usage in diagonal, for its bar are favorable to axial loads of compression and traction.

Based on Chaves [3], with the high efficiency of the latticework braces, it was possible to build very rigid lateral structures with the minimum addition of material, which makes it economical for the high quantity of different heights. With the addition of diagonal bars on the gantries, we noticed that the lateral efforts were primarily absorbed by such diagonal bars, relieving the moment in the beams and pillars, and keeping it mostly axial efforts of traction and compression; that is what makes such system so efficient. 


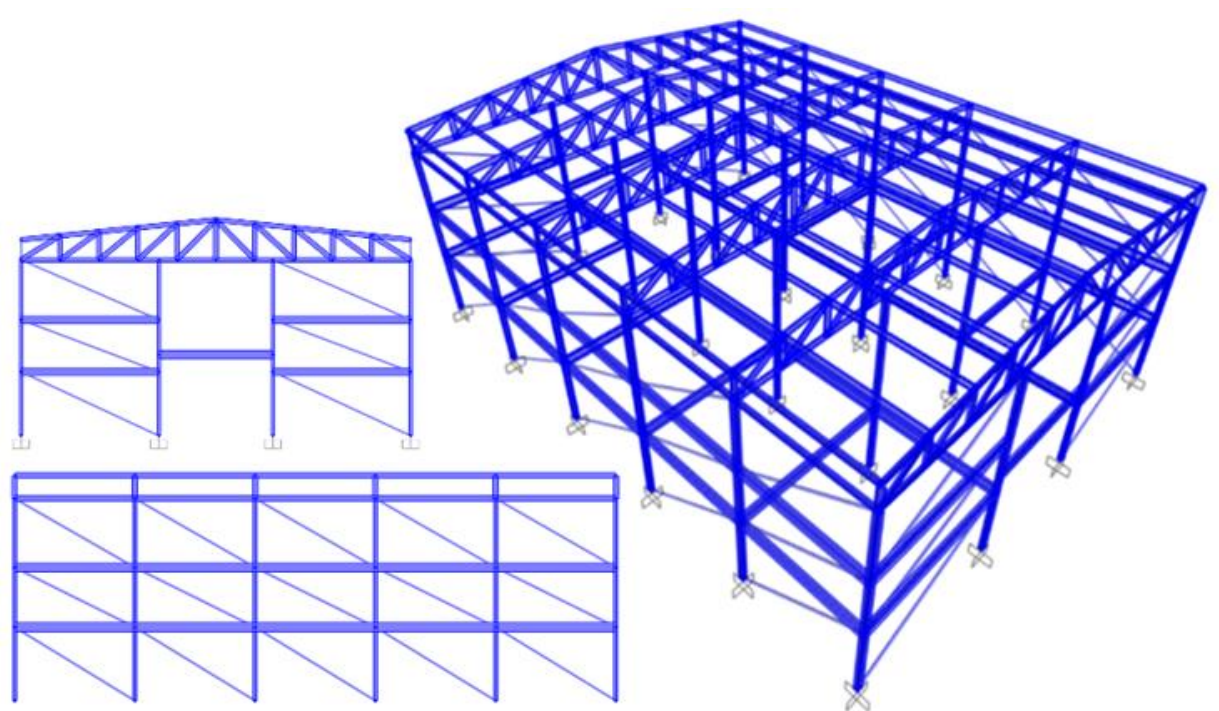

Figure 5 - Shed with simple diagonal brace

\subsubsection{Shed with double diagonal brace}

In such structure we maintained the use of a bar at each span, but they were inserted in different directions; the sequence was one to the right, and one to the left. This kind of shed is characterized as the double diagonal model, as presented in the figure 6.
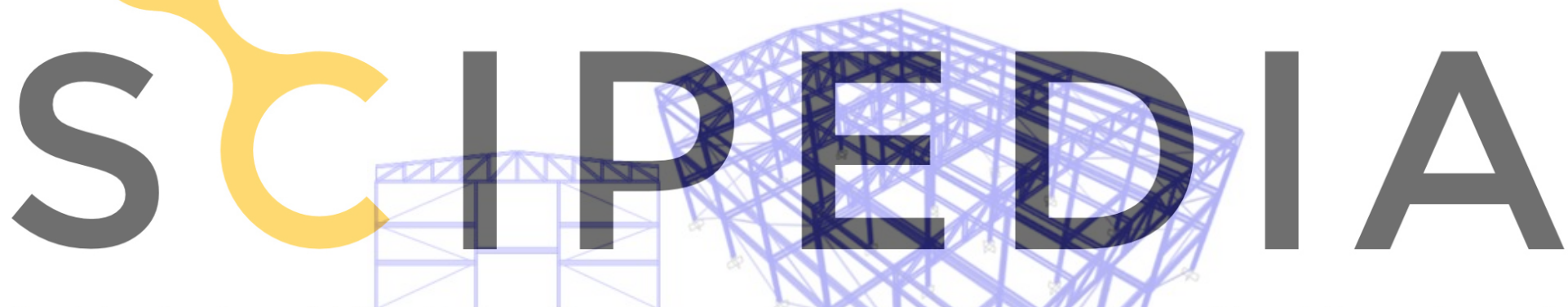

Register for free at https//www.scipedia.com to download the version without the watermark


Figure 6 - Shed with double diagonal brace

\subsubsection{Shed with inverted $V$ brace}

To the fourth structure, two bars inclined and put together in the center per span, and fixed on the upper beam were adopted. This arrangement is denominated as inverted $\mathrm{V}$, and it is illustrated in the figure 7. 


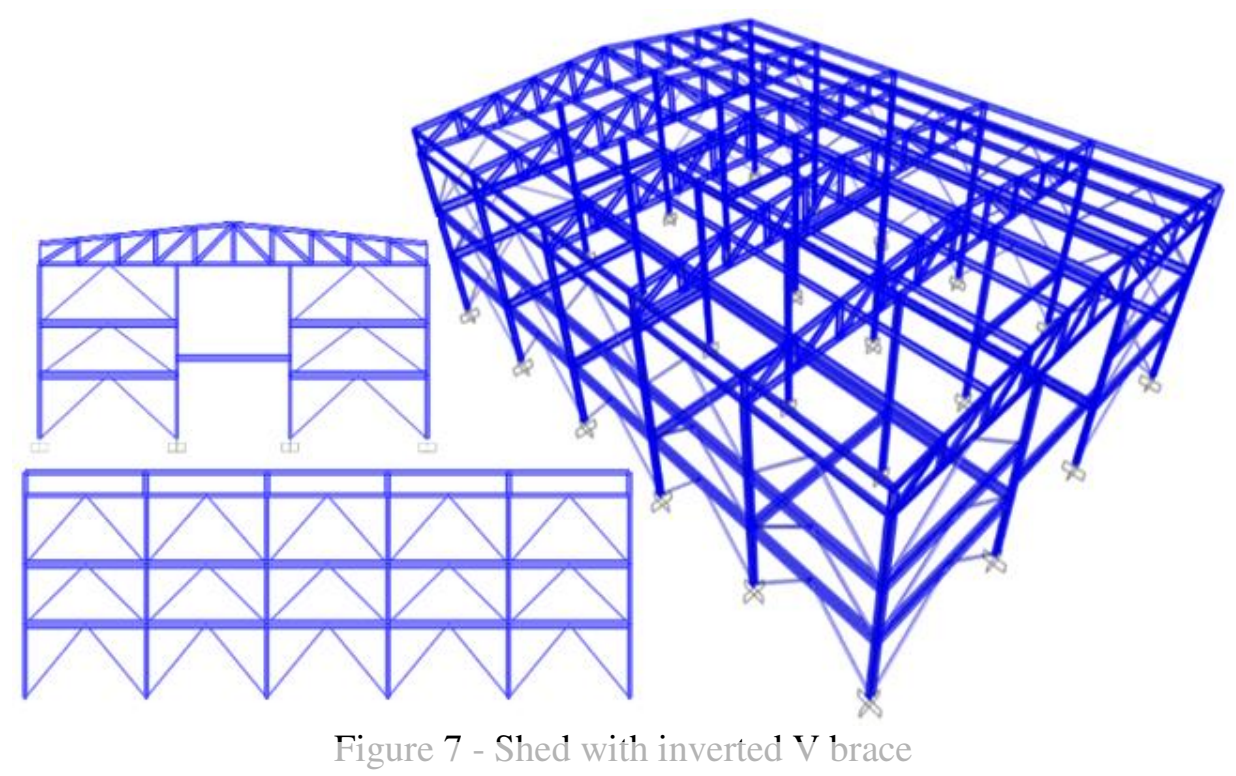

\subsection{Materials}

For all the modellings we adopted the same kind of steel. The ASTM A36 was used in the metallic profiles, for it is one of the most used steels in the civil construction. For the gauges, we used a variety of models due to the disposition of each element along the project, which

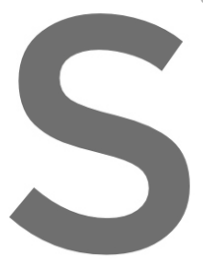
are presented in the Table 1
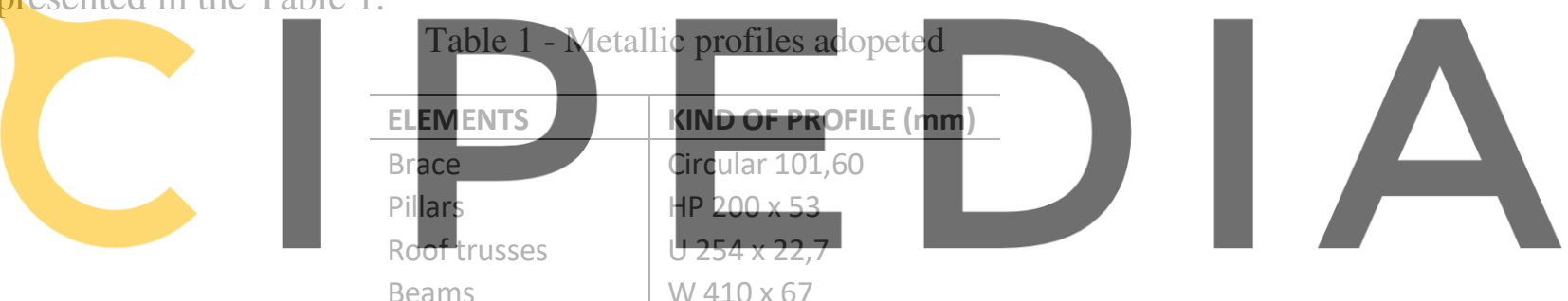

Register for free at https//www.scipedia.com to download the version without the watermark

\subsection{Wind load}

Wind is a natural phenomenon that presents temporal instability and random oscillation inside and average speed media. That said, the wind load analysis is an important criterion to the achievement of projects, and even in areas which there is no relevant action, for it does not act in a visible way, the wind action must be considered at some point during the operating life of the structure. The disorderly happenings of the wind oscillations make its study difficult in a deterministic way. Because of that, the studies on wind are made through statistic averages.

The NBR 6123/1988 stablishes the determination method of wind load, based on the demandable conditions once there is consideration of forces due to the static and dynamic actions of the wind for buildings calculations. Still in accordance to the norm, prevenient loads of the wind action depend on determined factors: Wind basic speed in the region, the kind of building occupation, topographic factor, building dimensions and roughness of the terrain.

The loads used in this analysis were calculated by the software named Visual Ventos, which is based on the NBR 6123/1988. In addition, it was applied the 2.0 version. Such software was developed by the University of Passo Fundo - UPF. It functionality is based on receiving input data with the building dimensions, base speed according to the location and calculation factors. Then it provides the load of the wind actions.

For the calculation of this load, which is based on the wind actions, we considered the 
following values:

a. Wind basic speed: $\mathrm{V} 0=35 \mathrm{~m} / \mathrm{s}$, related to the region of Brasília;

b. $\quad$ Topographic factor, S1: Plan terrain or weakly rugged. $\mathrm{S} 1=1,0$;

c. Roughness factor, S2: Category IV, terrains covered by numerous obstacles and little spaced in an urban, industrial or forest zone. Type B, all the building or part of building which the biggest horizontal or vertical dimension of the front surface is between $20 \mathrm{~m}$ and $50 \mathrm{~m}$. Height (z) equals to $10,93 \mathrm{~m}$. S2 $=0,84$.

d. Statistic factor, S3: Group 2, hotel and residence buildings, commercial and industrial buildings with high occupation factor. $\mathrm{S} 3=1,0$.

The characteristic speed V was calculated based on the Equation (1):

$$
V_{k}=35 \mathrm{~m} / \mathrm{s} \times 1,00 \times 0,84 \times 1,00=29,48 \mathrm{~m} / \mathrm{s}
$$

The dynamic pressure q was calculated based on the Equation (2) below:

$$
q=0,613 \times(29,48 \mathrm{~m} / \mathrm{s})^{2}=0,53 \mathrm{kN} / \mathrm{m}^{2}
$$

The aerodynamic and form coefficients of pressure for the analyzed gantry wall are related to the dimensions and characteristics of the structure seal. The external pressure coefficients that were found for such building, in which the wind is at $0^{\circ}$ and at $90^{\circ}$, were revealed through the Equation (3) that defines the building height, and the Equation (4) that defines the building proportion.

The relative building height is:
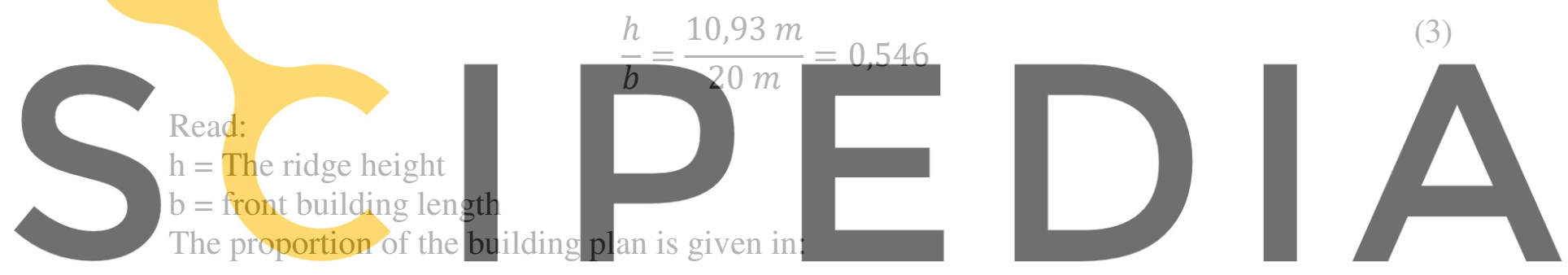

a $26 m$

(4)

Register for free at https//www.scipedia, $\overline{\overline{c o}} \overline{20}$ ta वơ ${ }^{3}$ nload the version without the watermark

Therefore, it was possible to find the external pressure coefficient, which is illustrated by the figure 8 and 9 for the distinct situations considering actions, which means to consider the wind at $9^{\circ}$ and $90^{\circ}$ :

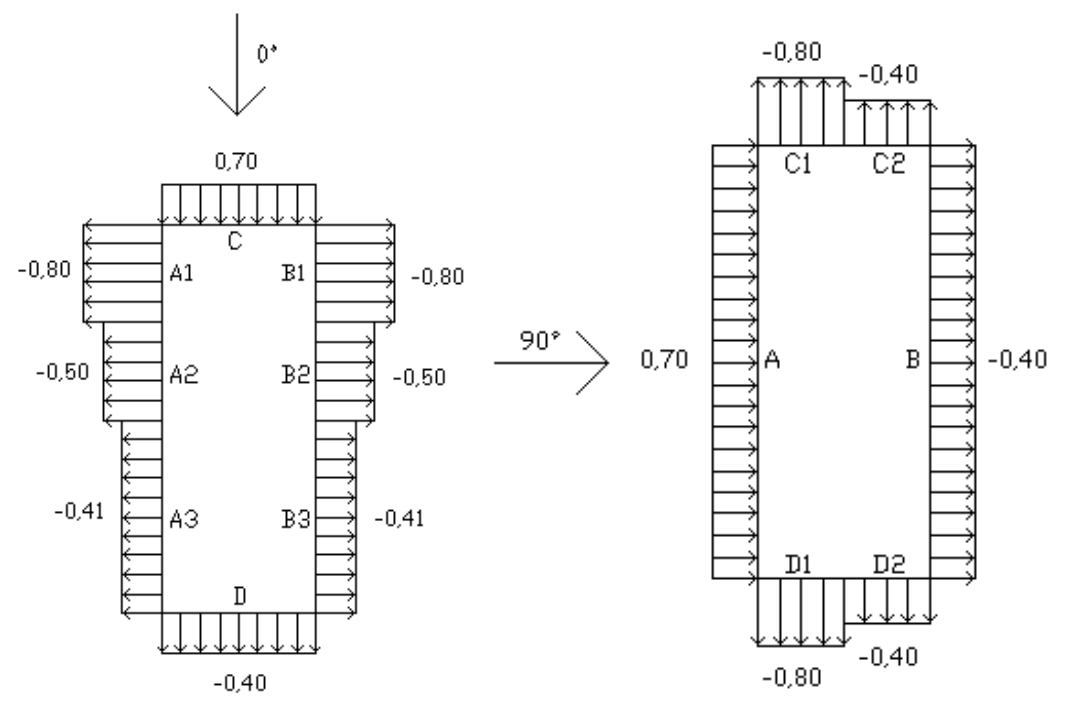

Figure 8 - External pressure coefficient on the building walls at $0^{\circ}$ and $90^{\circ}$ 
The different values to the coefficients are related to the application of the efforts on the part of the windward side of the parallel walls to the wind. For wind at 0 o the coefficients A1, A2, $\mathrm{A} 3, \mathrm{~B} 1, \mathrm{~B} 2$ and B3 are connected to a distance (positioning) between b/3 or a/4 (bigger among the values). For the wind at 90o the coefficients A, B, C1, C2, D1 and D2 the parameters were $2 \mathrm{~h}$ ou $\mathrm{b} / 2$ (lower between the two of them).

Besides the efforts (pressure coefficients) on the walls, the same analyzis has to be done for the roofs, because it is known that the region of the roofs is where it happens the maximum average of suction, which is already confimed by experiments at wind tunnels with inclinations between and $12^{\circ}$. The figure 9 presents results of coefficients for the roof.

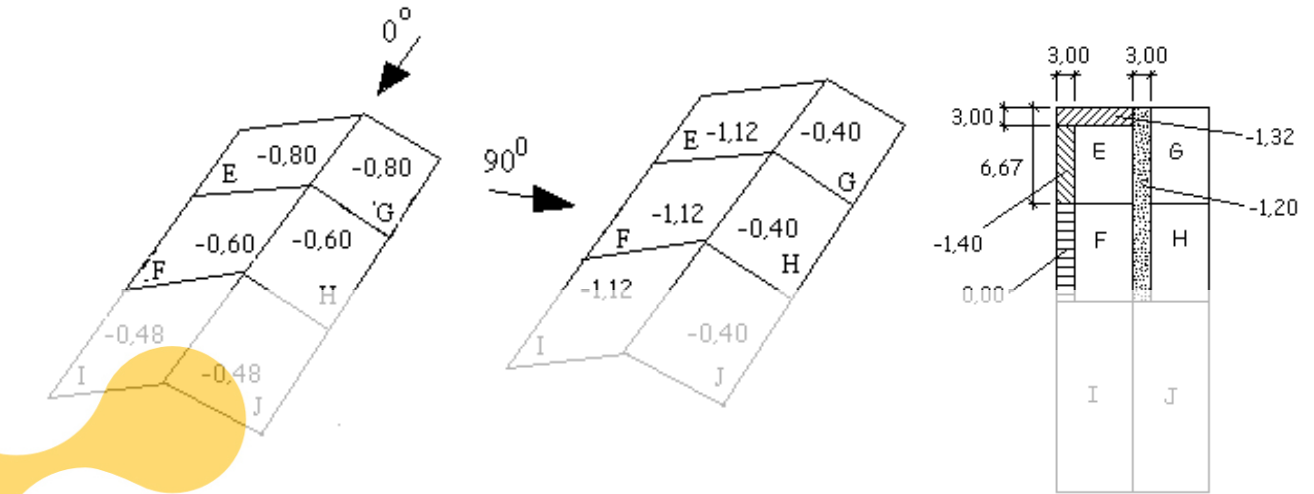

Figure 9 - External pressure coefficient: Cpe on the building roof at $0^{\circ}, 90^{\circ}$ and the average $\mathrm{CPE}$ respectively

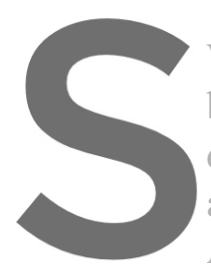

When considering the po
between $\mathrm{b} / 3$ or $\mathrm{a} / 4$ (the
directions, 0 o and $90 \mathrm{o}$
and $\mathrm{L}$ the parameters mu
As such construction ha
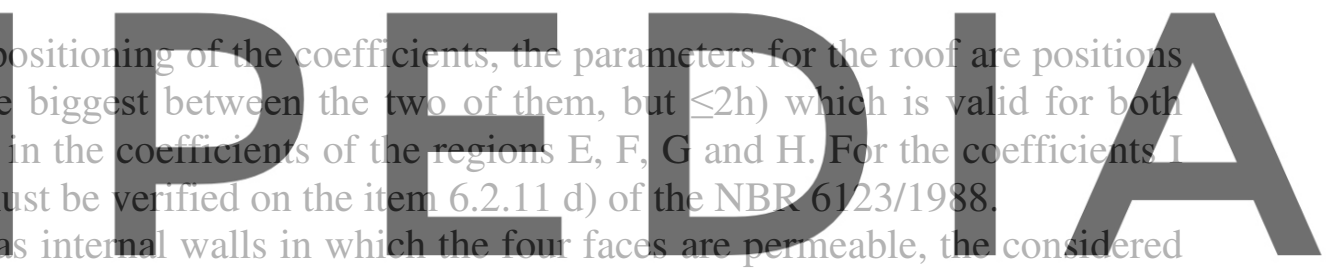

internal pressure was in CPI $=0$, according to the paragraph b from the item 6.2.5 of the NBR

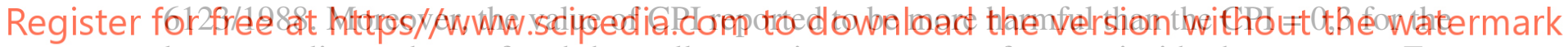
last one relieves the roof and the walls once it exerts some force to inside the structure. For this reason, it was possible to stablish combinations of the pressure coefficients at $0^{\circ}$ and $90^{\circ}$ as demonstrated by the figure 10 .
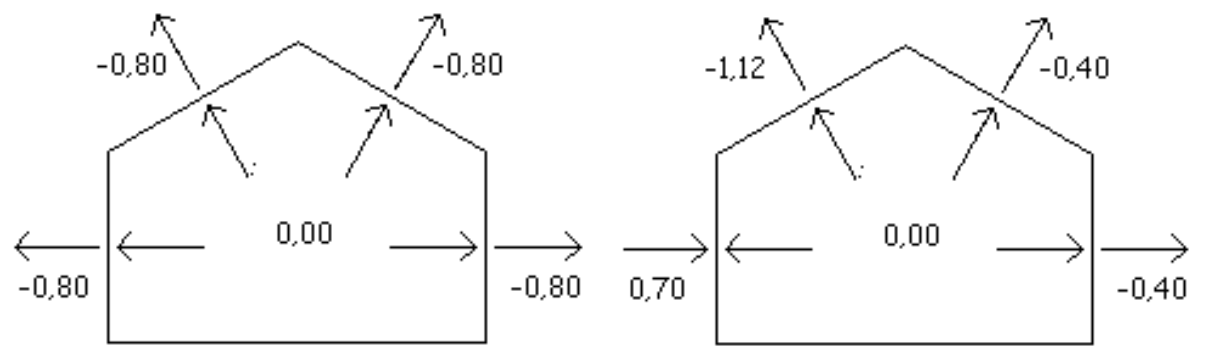

Figure 10 - Pressure coefficient combination at $0^{\circ}$ and $90^{\circ}$ respectively

As soon as the coefficients combination is finished, it is possible to find out the resultant efforts of the wind load due to the combinations of the actions for wind at $0^{\circ}$ and also at $90^{\circ}$ in the shed as the figure 11 illustrates, just like the final forces used, based on the Equation (5).

$$
F=(C p e-C p i) \times q \times A
$$

Read: 
Cpe = external form coefficient;

$\mathrm{Cpi}=$ internal form coefficient;

$\mathrm{q}=$ dynamic pressure and

$\mathrm{A}=$ Front area or perpendicular to the wind action
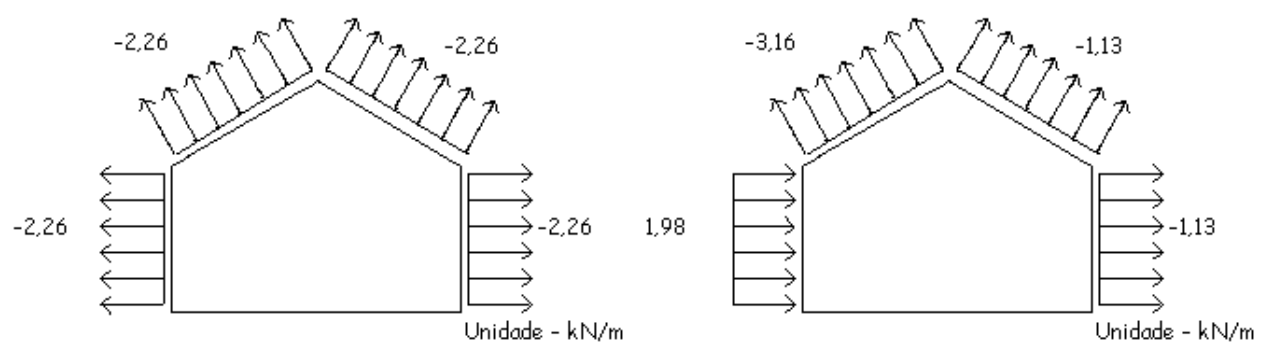

Figure 11 - Resultant efforts of the wind load at $0^{\circ}$ and $90^{\circ}$ respectively

\section{RESULTS AND DISCUSSIONS}

After updating data about the loads on the SAP2000, we identified horizontal deformations and displacements on the points considered for analysis. It is important to mention that results obtained and analyzed are only to the direction X and Y, once they are where occur the biggest displacements caused by wind loads and also where the braces work. First of all, it will be presented the result at the direction X, then at Y, both for analysis. Furthermore, this work analyzed only the walls of the external sealing structure of the shed, verifying possible displacements.

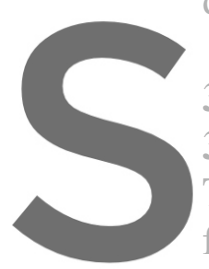

3.1 General deformations of the structure
3.1.1 Structure with no brace
The deformation of the structure with no brac
figure. It was verified a high solicitation of th
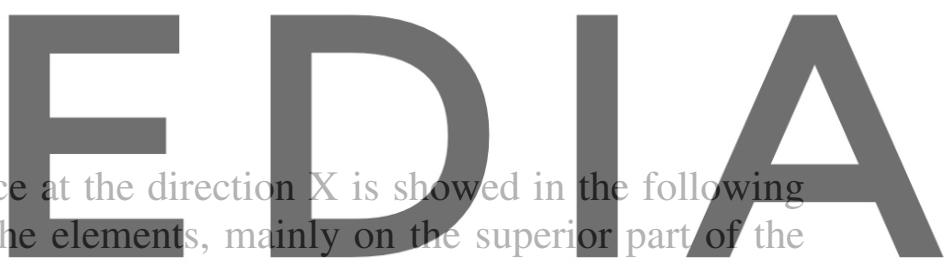
construction, as demonstrated in the figure 12. At the supportive regions, for they are build-in,

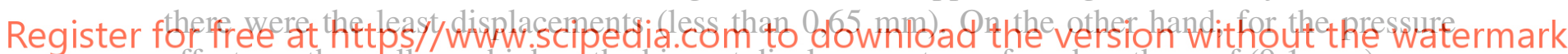
effects on the walls are higher, the biggest displacement was found on the roof $(9,1 \mathrm{~mm})$.

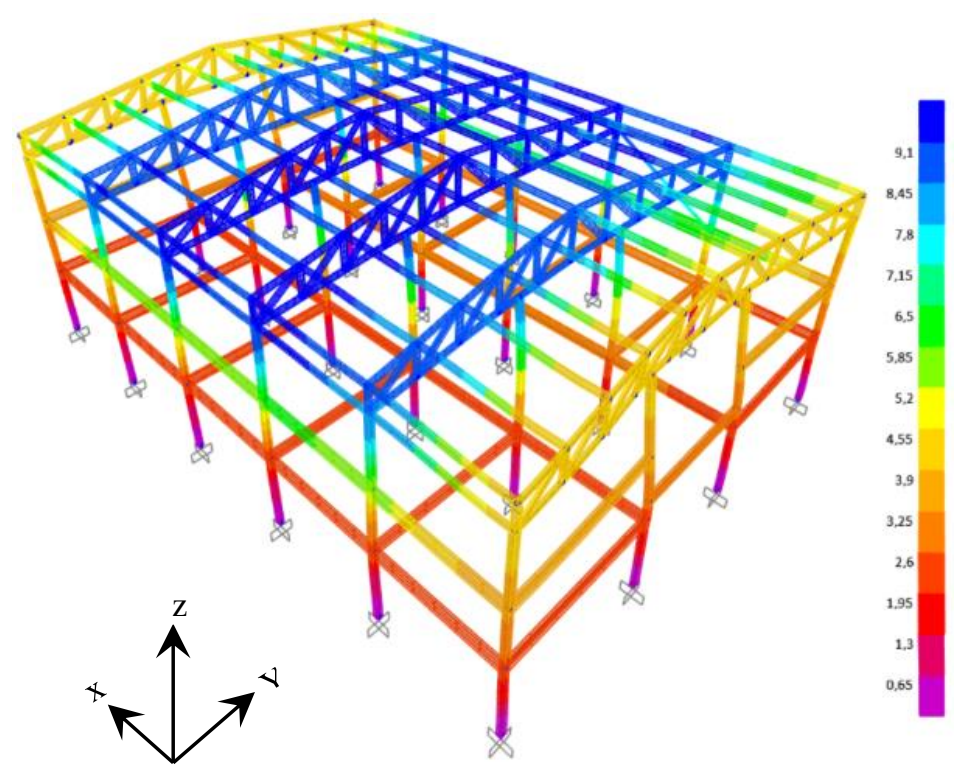

Figure 12 - Deformation in a structure with no brace - direction $\mathrm{X}$ 
The same way as done in the direction $\mathrm{X}$, there was an analysis considering the direction $\mathrm{Y}$, and it is presented in the figure 13. It is possible to observe that the wind load in this direction contributed to bigger displacements, most of all in the central part of the structure with no brace at all. From the analysis of the lateral gantry we noticed the structure displaced about $14,4 \mathrm{~mm}$ to $16, \mathrm{~mm}$ at some points; which are illustrated by the orange color.

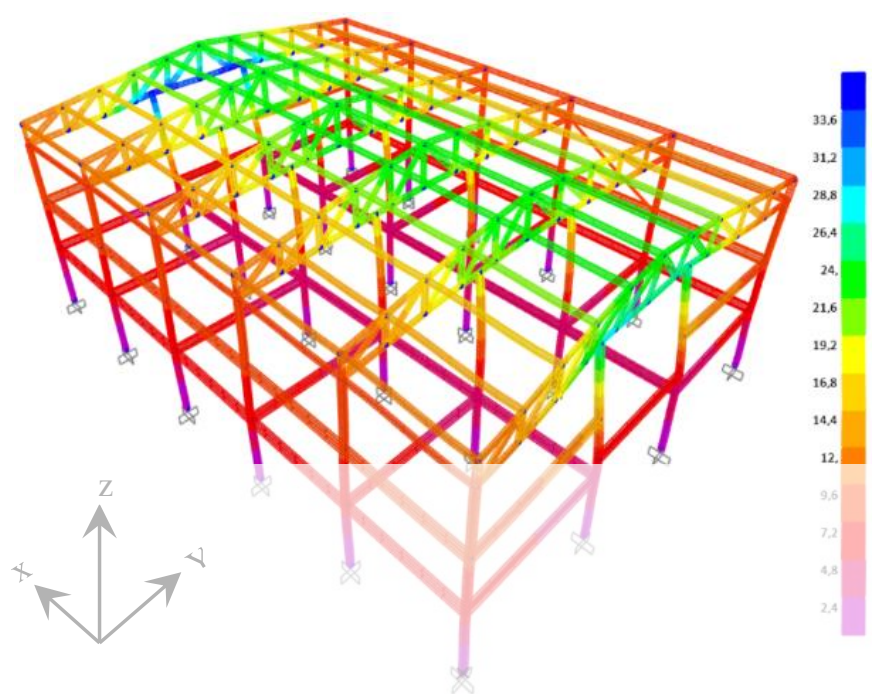

Figure 13 - Deformations in a structure with no brace - direction Y

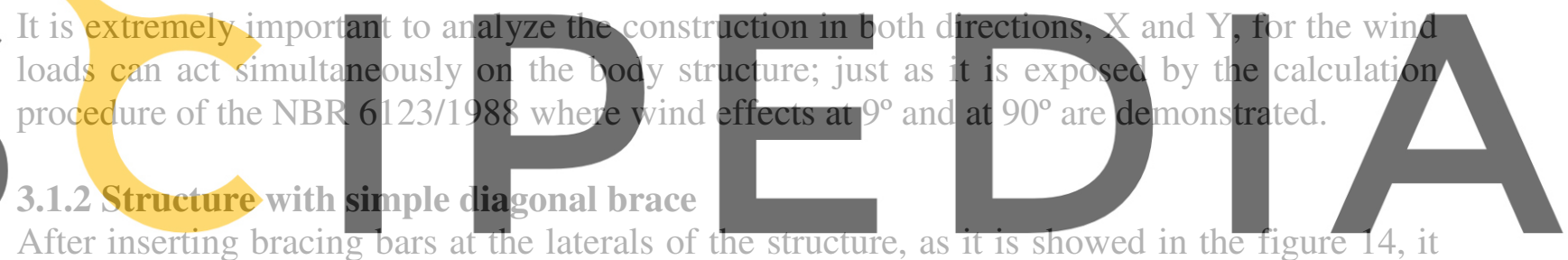

After inserting bracing bars at the laterals of the structure, as it is showed in the figure 14 , it

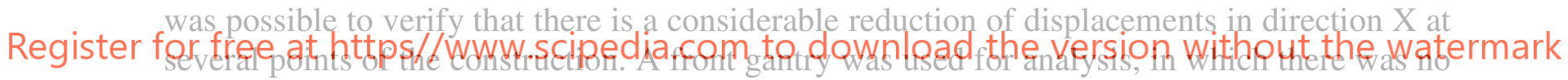

brace, and resulted 5,2 $\mathrm{mm}$ of displacement. With a bracing system in the diagonal, the same

gantry was able to displace oniy $1,5 \mathrm{~mm}$.

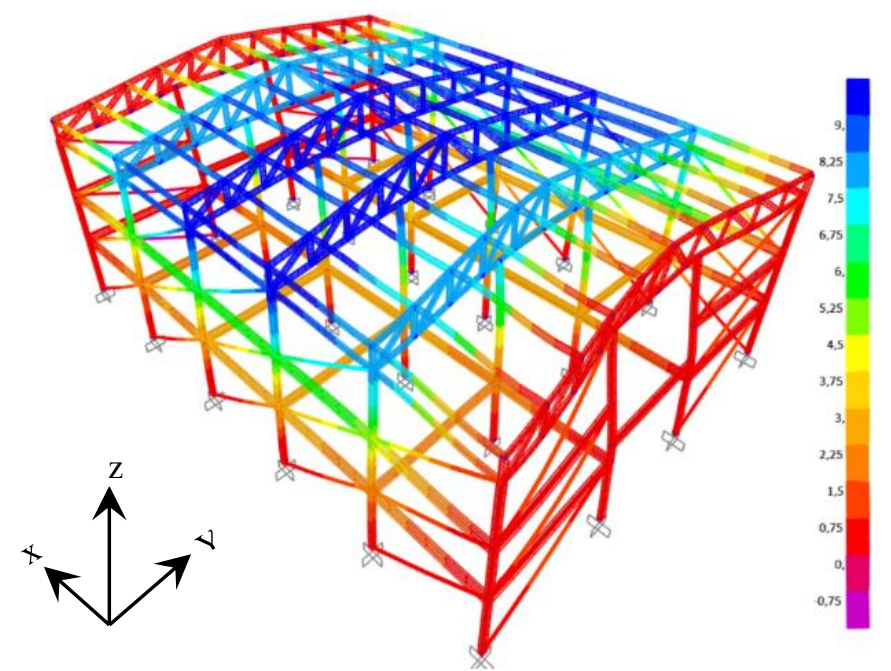

Figure 14 - Deformations in a structure with a simple diagonal brace - direction $\mathrm{X}$ 
In the direction $\mathrm{Y}$, which is presented in the figure 15, the decrease of displacements was not easily noticed as in the direction X. However, it is clear that there was a reduction that can be observed in the lateral part of the structure, for there were some points with 14,4 $\mathrm{mm}$ in average of displacement with no brace, and the ones with simple diagonal such displacement achieved no more than $12 \mathrm{~mm}$ at the same points.

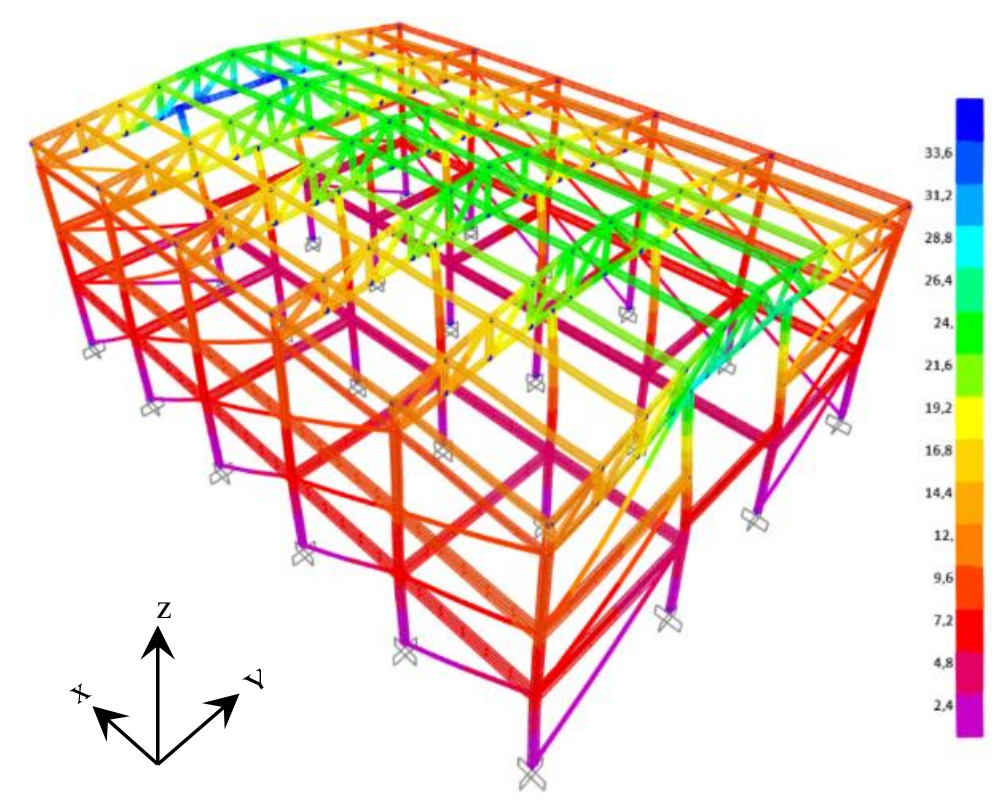

Figure 15 - Deformation in a structure with simple diagonal brace - direction Y

\subsubsection{Structure with double diagonal brace}

After inserting the double diagonal bracing system, the one illustrated in the figure 16, it can be told that displacements which were achieved as results in the direction $\mathrm{X}$ were similar to the ones from the simple diagonal bracing system. In there, we observed 1,5 $\mathrm{mm}$ of displacement at the same points as analyzed for the simple diagonal system.

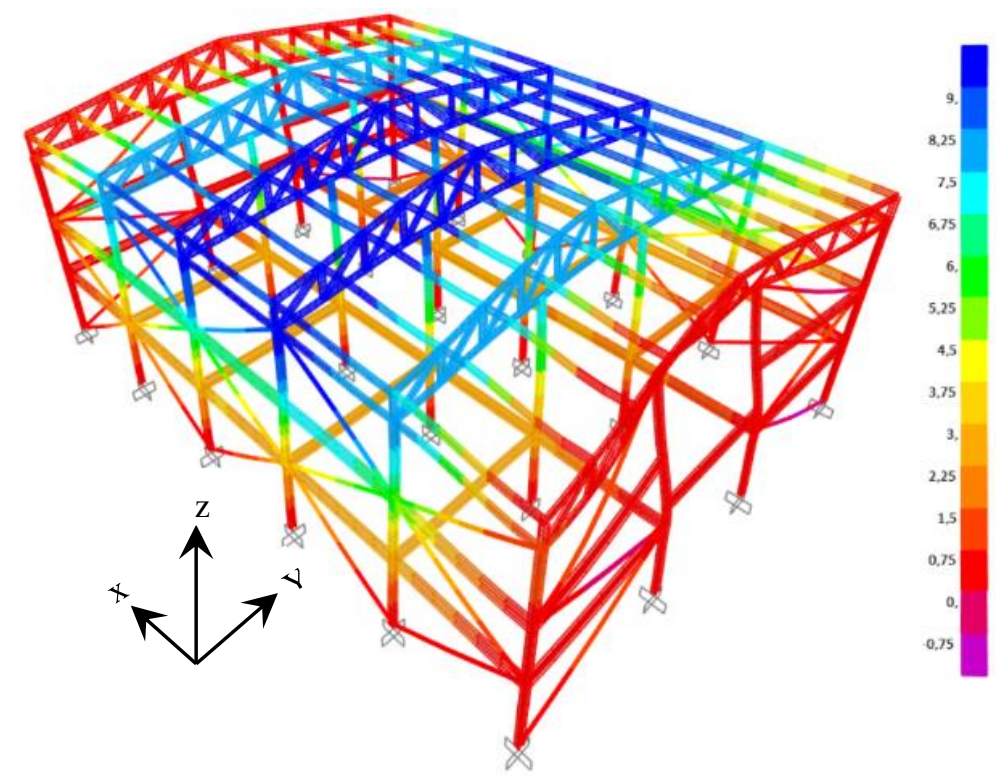

Figure 16 - Deformations in a structure with double diagonal brace - direction X 
In contrast, on the analyses of the direction Y, the double diagonal bracing system proved to be very efficient on the lateral gantry in question, as presented on the figure 17. The displacements which were verified vary from $0 \mathrm{~mm}$ to $2,2 \mathrm{~mm}$; this represents a significant reduction once we compare it to the simple diagonal brace that obtained displacements range of $9 \mathrm{~mm}$ to $12 \mathrm{~mm}$.

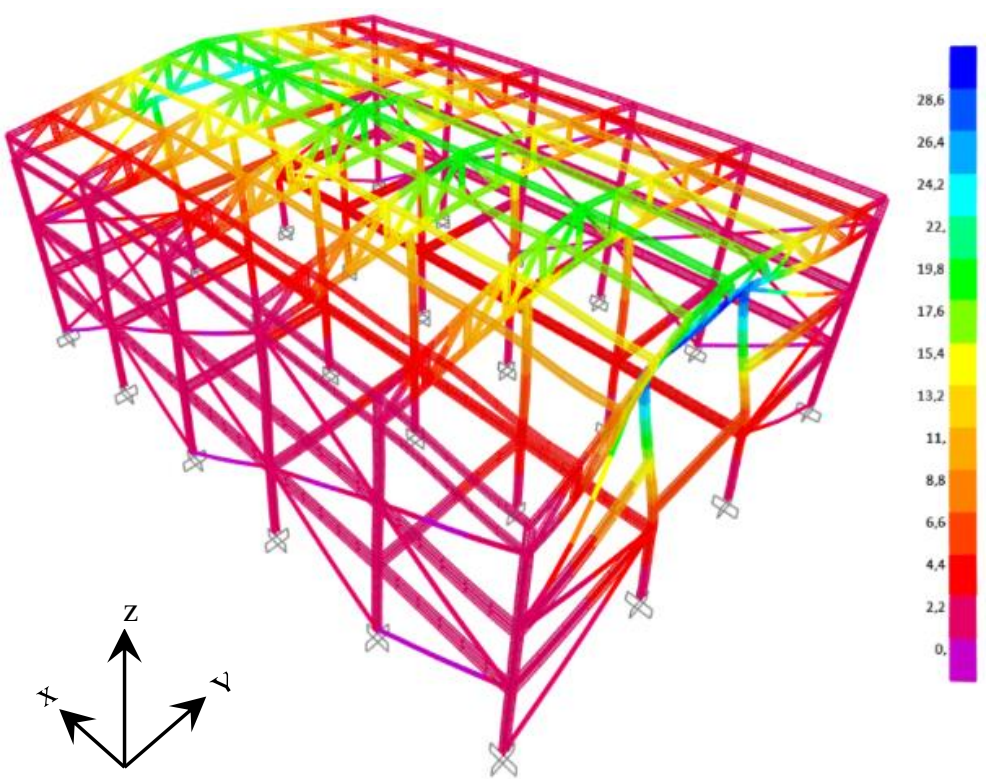

Figure 17 - Deformations in a structure with double diagonal brace - direction Y

\subsubsection{Structure with inverted $\mathrm{V}$ brace}

Considering the other bracing systems, it was made an analysis taking the inverted $\mathrm{V}$ brace system as the object of study. According to the figure 18, we can notice that in the direction $\mathrm{X}$ such type of brace presented better results in terms of decreasing displacements. From the front gantry, which was verified in the other systems, it can be noticed almost non-existent displacements; taking $0,7 \mathrm{~mm}$ as reference. Such reduction happens due to the increase on the lateral rigidity of the gantries. Once the inverted V brace is formed by bars with shorter spans, the displacements are also shorter than the usual.
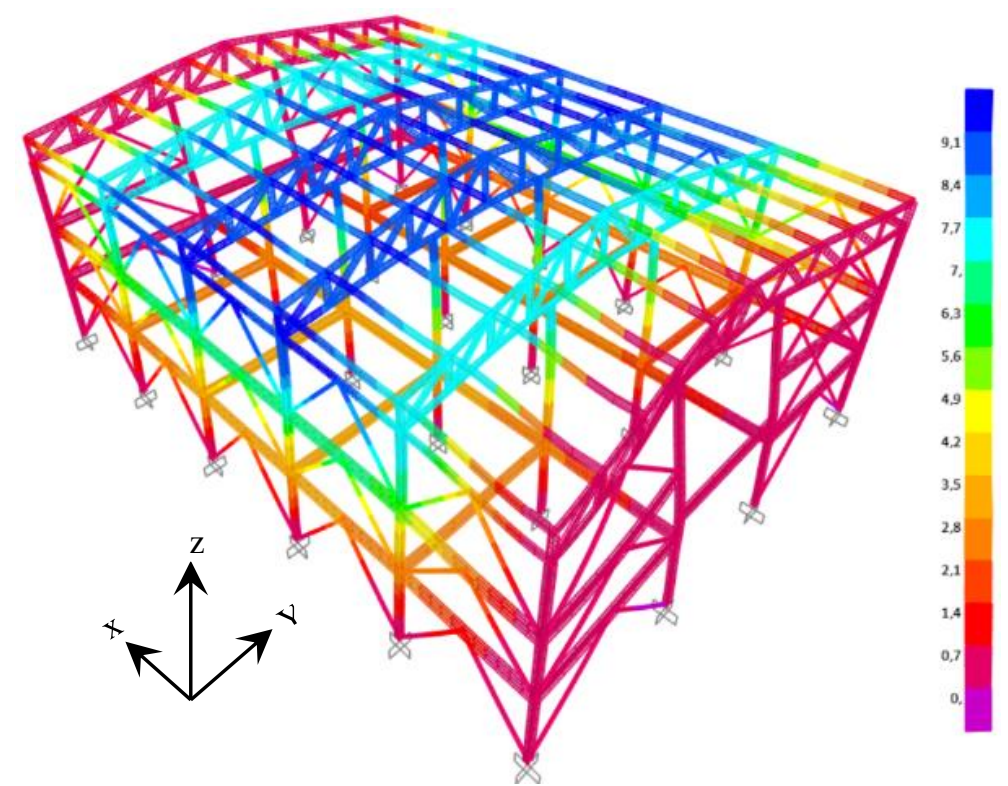

Figure 18 - Deformations in a structure with inverted V brace - direction X 
In the direction $\mathrm{Y}$, likewise the direction $\mathrm{X}$, this system also seemed to be very effective, being treated as similar to the displacements achieved by the double diagonal system. After all, the inverted $\mathrm{V}$ brace system is propitious to obtain more lateral rigidity due to have more bars and less spans. The maximum displacements found out on the lateral gantry analyzed, considering the inverted $\mathrm{V}$ brace, were of $2,2 \mathrm{~mm}$; just as presented in the following figure.

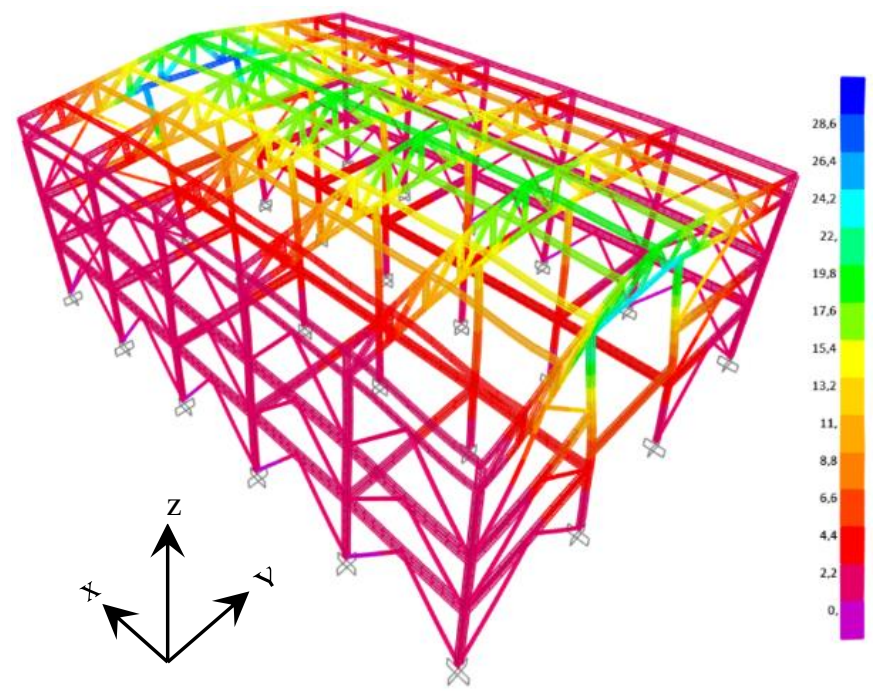

Figure 19 - Deformations in a structure with inverted V brace - direction Y

\subsection{Displacements at some considered points}

Considering a detailed analysis, 24 points along the nodes of the lateral façade of the structure were chosen in order to get an effective verification about the braces located in local contexts when considering the shed walls. Later, results of each one of these points in the four modeled structures were compared. The arrangements of such points can be seen in the figure 20 .

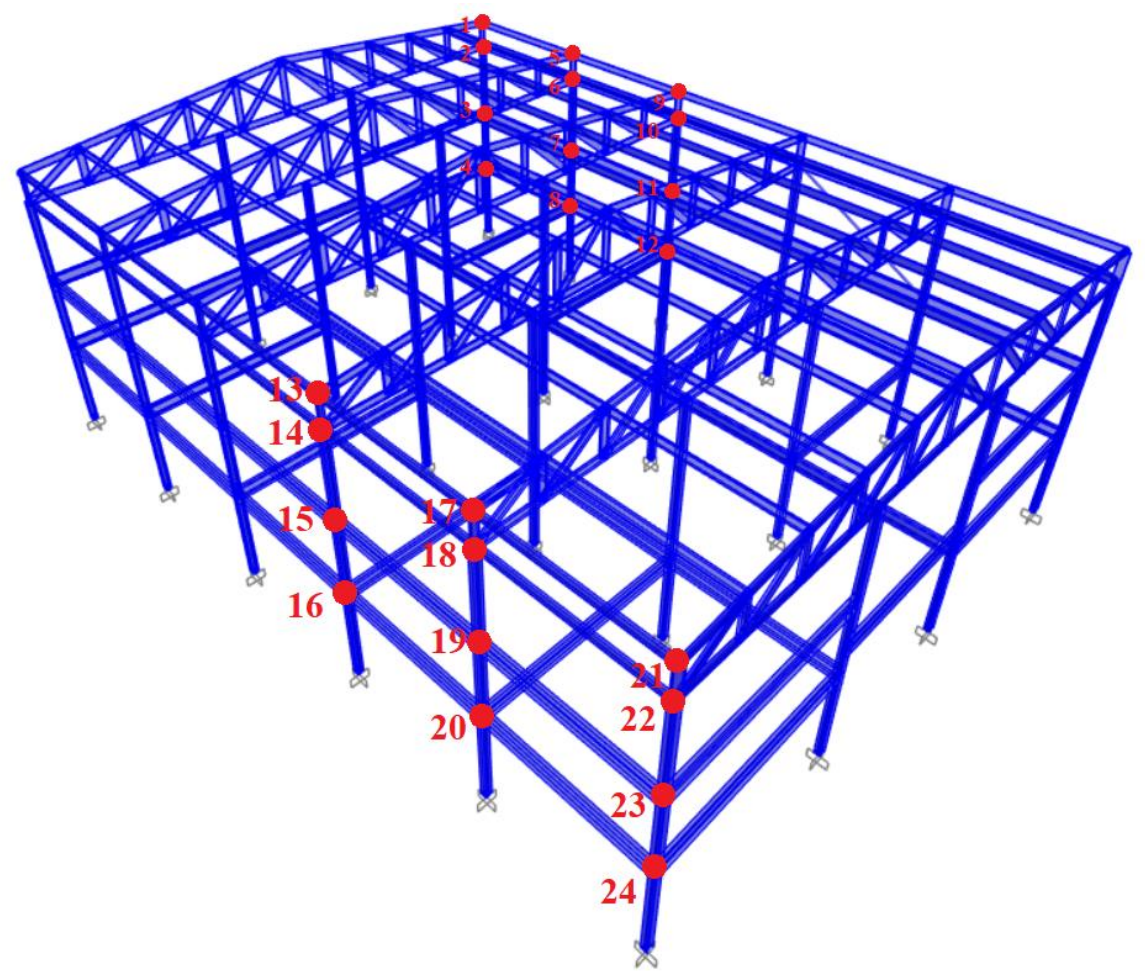

Figure 20 - Points to be analyzed in on the structures 
The following tables present displacements of all points of the sheds in question. For a better comprehension, it was done the standardization of these events in each point according to the Equation (6). Such standardization consists in dividing values of displacement by the higher value between them, and then change them into percentage in order to reproduce the comparisons.

$$
\text { STANDARDIZATION }=\frac{\text { Displacement value }}{\text { Higher displacement value in comparison }}
$$

Once we analyzed the displacements in the direction to X, which are exposed by the Table 2, we observed that more than half of the points had more displacement on the construction not braced, obviously for the structure has less elements of stiffness.

The structures with simple and double diagonal presented similar values between them in all the compared points. But, more than $30 \%$ of the displacements were a way less than the structure not braced.

The inverted V type was the one that resulted smaller displacements in almost $80 \%$ of the considered points. However, more than $30 \%$ of these values were less than $10 \%$ of the displacements in the not braced structure.

Table 2 - Displacements and standardizations in the direction X

\begin{tabular}{c|c|c|c|c|c|c|c|c}
\hline \multicolumn{2}{c}{ DISLPLCEMENT IN THE DIRECTION X [MM] } & \multicolumn{3}{c}{ STANDARDIZATION } \\
\hline \multirow{3}{*}{ Nodes } & \multicolumn{3}{|c|}{ Type of brace } & \multicolumn{3}{|c}{ Type of brace } \\
\cline { 2 - 9 } & With no brace & $\begin{array}{c}\text { Simple } \\
\text { Diagonal }\end{array}$ & $\begin{array}{c}\text { Double } \\
\text { Diagona } \\
1\end{array}$ & $\begin{array}{c}\text { Inverted } \\
\text { V }\end{array}$ & With no brace & $\begin{array}{c}\text { Simple } \\
\text { Diagona } \\
1\end{array}$ & $\begin{array}{c}\text { Double } \\
\text { Diagona } \\
1\end{array}$ & $\begin{array}{c}\text { Inverted } \\
\text { V }\end{array}$ \\
\hline 1 & 4,456 & 0,709 & 0,642 & 0,333 & $100,00 \%$ & $15,91 \%$ & $14,41 \%$ & $7,47 \%$ \\
2 & 4,466 & 0,799 & 0,659 & 0,361 & $100,00 \%$ & $17,89 \%$ & $14,76 \%$ & $8,08 \%$ \\
3 & 3,37 & 0,594 & 0,465 & 0,262 & $100,00 \%$ & $17,63 \%$ & $13,80 \%$ & $7,77 \%$ \\
4 & 2,420 & 0,373 & 0,301 & 0,167 & $100,00 \%$ & $15,41 \%$ & $12,44 \%$ & $6,90 \%$ \\
5 & 8,486 & 7,785 & 7,705 & 7,568 & $100,00 \%$ & $91,74 \%$ & $90,80 \%$ & $89,18 \%$ \\
6 & 8,491 & 7,856 & 7,704 & 7,572 & $100,00 \%$ & $92,52 \%$ & $90,73 \%$ & $89,18 \%$ \\
7 & 5,366 & 5,526 & 4,782 & 4,673 & $97,10 \%$ & $100,00 \%$ & $86,54 \%$ & $84,56 \%$ \\
8 & 2,208 & 2,475 & 1,926 & 1,904 & $89,21 \%$ & $100,00 \%$ & $77,82 \%$ & $76,93 \%$ \\
9 & 9,163 & 9,212 & 9,115 & 9,058 & $99,47 \%$ & $100,00 \%$ & $98,95 \%$ & $98,33 \%$ \\
10 & 9,158 & 9,272 & 9,106 & 9,049 & $98,77 \%$ & $100,00 \%$ & $98,21 \%$ & $97,59 \%$ \\
11 & 5,79 & 6,639 & 5,792 & 5,733 & $87,21 \%$ & $100,00 \%$ & $87,24 \%$ & $86,35 \%$ \\
12 & 2,337 & 2,967 & 2,358 & 2,34 & $78,77 \%$ & $100,00 \%$ & $79,47 \%$ & $78,87 \%$ \\
13 & 9,166 & 9,218 & 9,167 & 9,058 & $99,44 \%$ & $100,00 \%$ & $99,45 \%$ & $98,26 \%$ \\
14 & 9,225 & 9,133 & 9,231 & 9,122 & $99,94 \%$ & $98,94 \%$ & $100,00 \%$ & $98,82 \%$ \\
15 & 6,718 & 5,861 & 6,754 & 6,657 & $99,47 \%$ & $86,78 \%$ & $100,00 \%$ & $98,56 \%$ \\
16 & 2,918 & 2,347 & 2,942 & 2,917 & $99,18 \%$ & $79,78 \%$ & $100,00 \%$ & $99,15 \%$ \\
17 & 8,491 & 7,788 & 7,668 & 7,57 & $100,00 \%$ & $91,72 \%$ & $90,31 \%$ & $89,15 \%$ \\
18 & 8,561 & 7,707 & 7,741 & 7,638 & $100,00 \%$ & $90,02 \%$ & $90,42 \%$ & $89,22 \%$ \\
19 & 6,236 & 4,809 & 5,605 & 5,559 & $100,00 \%$ & $77,12 \%$ & $89,88 \%$ & $89,14 \%$ \\
20 & 2,746 & 1,906 & 2,464 & 2,445 & $100,00 \%$ & $69,41 \%$ & $89,73 \%$ & $89,04 \%$ \\
21 & 4,449 & 0,734 & 0,639 & 0,338 & $100,00 \%$ & $16,50 \%$ & $14,36 \%$ & $7,60 \%$ \\
22 & 4,576 & 0,718 & 0,771 & 0,413 & $100,00 \%$ & $15,69 \%$ & $16,85 \%$ & $9,03 \%$ \\
23 & 3,583 & 0,567 & 0,541 & 0,313 & $100,00 \%$ & $15,82 \%$ & $15,10 \%$ & $8,74 \%$ \\
24 & 2,456 & 0,356 & 0,351 & 0,188 & $100,00 \%$ & $14,50 \%$ & $14,29 \%$ & $7,65 \%$ \\
\hline
\end{tabular}


For the direction $\mathrm{Y}$, the displacements are posted in the Table 3. As in the direction X, the displacements were smaller in the structures not braced. The ones from analyzed points in the braced structures were only about $10 \%$ of the values of the structure not braced, which characterizes the effectiveness and importance of the bracing system in the constructions.

The inverted $\mathrm{V}$ type of brace also presented better answers in comparison to the displacements which were applied and analysed.

Table 3 - Displacements and standardizations in the direction Y

\begin{tabular}{|c|c|c|c|c|c|c|c|c|}
\hline \multicolumn{5}{|c|}{ DISLPLACEMENT IN THE DIRECTION Y [MM] } & \multirow{2}{*}{\multicolumn{4}{|c|}{$\begin{array}{c}\text { STANDARDIZATION } \\
\text { Type of brace }\end{array}$}} \\
\hline \multirow[b]{2}{*}{ Nodes } & \multicolumn{4}{|c|}{ Type of brace } & & & & \\
\hline & With no brace & $\begin{array}{c}\text { Simple } \\
\text { Diagona } \\
1 \\
\end{array}$ & $\begin{array}{c}\text { Double } \\
\text { Diagona } \\
1 \\
\end{array}$ & $\begin{array}{c}\text { Inverted } \\
\mathrm{V}\end{array}$ & With no brace & $\begin{array}{c}\text { Simple } \\
\text { Diagona } \\
1 \\
\end{array}$ & $\begin{array}{c}\text { Double } \\
\text { Diagona } \\
1 \\
\end{array}$ & $\begin{array}{c}\text { Inverted } \\
\mathrm{V}\end{array}$ \\
\hline 1 & 9,645 & 0,430 & 0,366 & 0,249 & $216,45 \%$ & $9,65 \%$ & $8,21 \%$ & $5,59 \%$ \\
\hline 2 & 9,484 & 0,423 & 0,359 & 0,263 & $212,36 \%$ & $9,47 \%$ & $8,04 \%$ & $5,89 \%$ \\
\hline 3 & 7,497 & 0,330 & 0,266 & 0,195 & $222,46 \%$ & $9,79 \%$ & $7,89 \%$ & $5,79 \%$ \\
\hline 4 & 5,261 & 0,205 & 0,175 & 0,137 & $217,40 \%$ & $8,47 \%$ & $7,23 \%$ & $5,66 \%$ \\
\hline 5 & 9,643 & 0,433 & 0,369 & 0,247 & $113,63 \%$ & $5,10 \%$ & $4,35 \%$ & $2,91 \%$ \\
\hline 6 & 9,466 & 0,398 & 0,318 & 0,216 & $111,48 \%$ & $4,69 \%$ & $3,75 \%$ & $2,54 \%$ \\
\hline 7 & 7,488 & 0,323 & 0,259 & 0,172 & $135,50 \%$ & $5,85 \%$ & $4,69 \%$ & $3,11 \%$ \\
\hline 8 & 5,254 & 0,202 & 0,160 & 0,116 & $212,28 \%$ & $8,16 \%$ & $6,46 \%$ & $4,69 \%$ \\
\hline 9 & 9,642 & 0,432 & 0,369 & 0,241 & $104,67 \%$ & $4,69 \%$ & $4,01 \%$ & $2,62 \%$ \\
\hline 10 & 9,461 & 0,389 & 0,318 & 0,192 & $102,04 \%$ & $4,20 \%$ & $3,43 \%$ & $2,07 \%$ \\
\hline 11 & 7,487 & 0,321 & 0,252 & 0,156 & $112,77 \%$ & $4,84 \%$ & $3,80 \%$ & $2,35 \%$ \\
\hline 12 & 5,253 & 0,204 & 0,159 & 0,104 & $177,05 \%$ & $6,88 \%$ & $5,36 \%$ & $3,51 \%$ \\
\hline 13 & 9,618 & 0,982 & 0,373 & 0,237 & $104,34 \%$ & $10,65 \%$ & $4,05 \%$ & $2,57 \%$ \\
\hline 14 & 9,442 & 0,310 & 0,314 & 0,186 & $102,29 \%$ & $3,36 \%$ & $3,40 \%$ & $2,01 \%$ \\
\hline 15 & 7,485 & 0,245 & 0,262 & 0,149 & $110,82 \%$ & $3,63 \%$ & $3,88 \%$ & $2,21 \%$ \\
\hline 16 & 5,254 & 0,143 & 0,162 & 0,098 & $178,59 \%$ & $4,86 \%$ & $5,51 \%$ & $3,33 \%$ \\
\hline 17 & 9,633 & 0,387 & 0,388 & 0,244 & $113,45 \%$ & $4,56 \%$ & $4,57 \%$ & $2,87 \%$ \\
\hline 18 & 9,461 & 0,302 & 0,347 & 0,197 & $110,51 \%$ & $3,53 \%$ & $4,05 \%$ & $2,30 \%$ \\
\hline 19 & 7,497 & 0,235 & 0,272 & 0,152 & $120,22 \%$ & $3,77 \%$ & $4,36 \%$ & $2,44 \%$ \\
\hline 20 & 5,265 & 0,133 & 0,174 & 0,099 & $191,73 \%$ & $4,84 \%$ & $6,34 \%$ & $3,61 \%$ \\
\hline 21 & 9,649 & 0,395 & 0,401 & 0,251 & $216,88 \%$ & $8,88 \%$ & $9,01 \%$ & $5,64 \%$ \\
\hline 22 & 9,49 & 0,311 & 0,372 & 0,220 & $207,39 \%$ & $6,80 \%$ & $8,13 \%$ & $4,81 \%$ \\
\hline 23 & 7,516 & 0,233 & 0,296 & 0,161 & $209,77 \%$ & $6,50 \%$ & $8,26 \%$ & $4,49 \%$ \\
\hline 24 & 5,28 & 0,178 & 0,184 & 0,104 & $214,98 \%$ & $7,25 \%$ & $7,49 \%$ & $4,23 \%$ \\
\hline
\end{tabular}

In general, all the bracing sheds tend to limit displacements on the constructions, which restricts the appearance of 2 nd order effects in verifications of the Usage Limit State. In addition, it is important to mention that they act mainly on the mobility just as on the structure resistance, receiving lateral loads, and applying them to the floor and rigid nodes of linking elements among the pillars of the gantries. The structural stability is obtained through the braces which are applied along all the building height; resulting in more stiffness.

The figure 21 introduces the working principle of the method, which in the first case the efforts are distributed among elements, such as beams and pillars, to the foundation. However, the elements basically suffer the bending efforts. In the second case, with the inverted V 
brace, the main function of the structures is also the redirection of efforts, but due to linking elements of the braced (rigid nodes) there is an increase of stiffness and the bending efforts are changed into traction and compression in the diagonals.
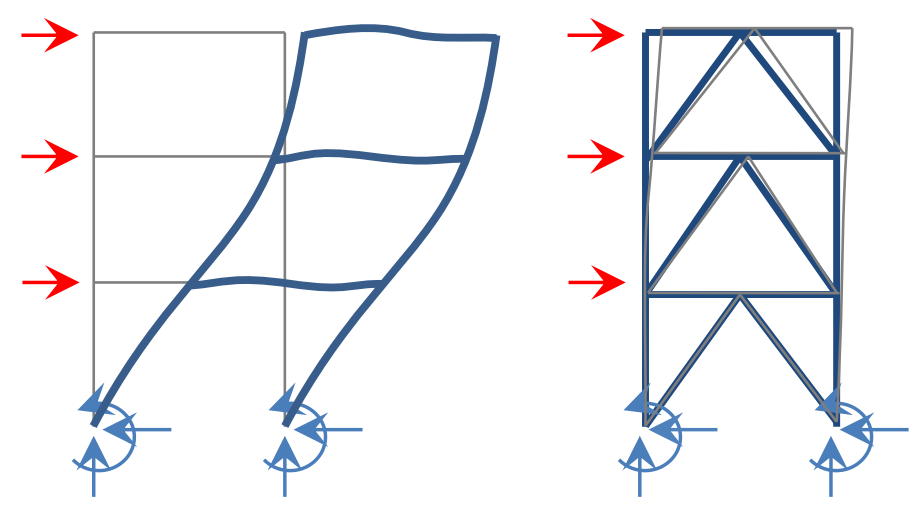

Figure 21 - Distribution principle of efforts in gantries

In order to define the best usage of the inverted $\mathrm{V}$ brace, it is important to consider that bending efforts of the not braced shed are changed into basic efforts of traction and compression, once they are result of a bending torque.

\section{CONCLUSION}

It was compared, by the use of the software named SAP2000, four structures of the same shed: one not braced and three with distinct types of brace. It was adopted a wind load calculated from the NBR 6123/1988. From this point on, the deformations in each structure were analyzed in a total of 24 points which were chosen in the lateral of the shed. After such analyses, the importance of the use of braces in metallic structures which are subjected to wind load was clear; after all, the displacements decreased drastically.

It was also verified that in most of the cases the simple and double diagonal braces obtained values really similar one to another, which shows that alternating bars arrangement will not be synonym of significant improvement of the structure stability.

The best performance is verified on the inverted $\mathrm{V}$ brace, once it presents smaller displacements in almost all the comparisons made during the experiment in view of the stiffness which was found by this method.

\section{REFERENCES}

[1]. ABNT, A. B. de Normas Técnicas. NBR 6123: Forças devidas ao vento em edificações. Associação Brasilera de Normas Técnicas, p. 66, 1988.

[2]. Carneiro, R. B. Controle semi-ativo de vibrações em estruturas utilizando amortecedor magnetorreológico. Universidade de Brasília, p. 154, 2009.

[3]. Chaves, J. R. F. Análise dinâmica de pórticos metálicos contraventados. Universidade de Brasília, p. 93, 2009.

[4]. Chávez, E. S. Análise estrutural de edifício alto submetido às pressões flutuantes induzidas pela ação do vento. Universidade Federal de Minas, p. 135, 2006.

[5]. Katkar, D. D.; Phadtare, N. P. Comparative study of an industrial pre-engineered building with conventional steel building. international research journal of engineering and technology (irjet), p. 127-133, 2018.

[6]. Matos, R. C. B. de. Sistemas de contraventamentos em edifícios de estrutura metálica. Faculdade de Tecnologia e Ciências Sociais Aplicadas - FATECS, p. 65, 2014. 
[7]. Pattanshetti, S., Kulkarni, S. M. Comparative study on the economy between preengineered and conventional steel buildings. international research journal of engineering and technology (irjet), p. 2708-2711, 2017.

[8]. Smith, B. S.; Coull, A. Tall building structures: analysis and design. Canadá: Jonh Wiley \& Sons, inc., 1991.

[9]. Titiksh, A., Dewangan, A., Khandelwal, A., \& Sharma, A. Comparative study of conventional steel building and pre-engineered building to be used as an industrial shed. International Journal of Engineering Research and Applications, p. 5(11), 2015. 